Proceedings

\title{
Different Development of Fundamental Movement Skill Vary by Sex: Evidence from Chinese 6-year-old Children ${ }^{+}$
}

\author{
Shudan Zhang ${ }^{1}$ and Qian Chen ${ }^{2, *}$ \\ 1 College of Physical Education and Health Sciences, Zhejiang Normal University, Jinhua 321004, Zhejiang, \\ China; 532625957@qq.com \\ 2 Zhejiang Sports Science Institute, Hangzhou 310004, Zhejiang, China; cq_chenqian@hotmail.com \\ * Correspondence: cq_chenqian@hotmail.com; Tel. +86-139-0653-6352
}

Publisher's Note: MDPI stays neutral with regard to jurisdictional claims in published maps and institutional affiliations.

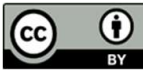

Copyright: (c) 2020 by the authors. Submitted for possible open access publication under the terms and conditions of the Creative Commons Attribution (CC BY) license (http://creativecommons.org/licenses /by/4.0/).

\begin{abstract}
This study conducted to assess and explore the gender-based differences in gross motor skill development of 6-year-old Chinese children. All participants, 6 years of age (254 males and 262 females), from 7 kindergartens in Hangzhou, a city of Zhejiang Province, China. Gross motor skills, including six locomotor and seven object control skills, were assessed using the test of gross motor development, third edition (TGMD-3). All subjects performed two trials of each gross motor skill, and the performances were video-recorded and scored. Assessment procedures were performed according to the standardized guidelines of the TGMD-3. The score of locomotor $(31.57 \pm 5.97)$ was higher than that of object control (29.09 \pm 6.72$)$. Furthermore, boys had significantly higher object-control $(\mathrm{p}=0.010)$ and Gross Motor Skill scores $(\mathrm{p}=0.033)$ than girls. In the locomotor test, boys were better than girls in the run $(p=0.000)$ and girls were better than boys in the $\operatorname{skip}(p=0.031)$. There are significant differences between boys and girls in the test of object con$\operatorname{trol}(p=0.002)$, such as underhand throw $(p=0.001)$, two hand catch $(p=0.006)$,forehand strike self-bounced ball $(\mathrm{p}=0.042)$, two-handed strike of a stationary ball $(\mathrm{p}=0.000)$, kick a stationary ball $(\mathrm{p}=0.000)$, and boys are better than girls. These r2esults are partly consistent with those in other countries and regions but also have local characteristics. There are biological and sociological reasons for the gender differences in fundamental motor skills of 6-year-old children. It is recommended to strengthen the training of girls' object control motor skills and improve the moderate to vigorous-intensity physical activity (MVPA) among females.
\end{abstract}

Keywords: Children; Motor development; Locomotor; Object control; Assessment; Gender

\section{Introduction}

Physical activity brings a wide range of health benefits of life.[1]. Although governments all over the world attach great importance of it, the physical activity of young people and children is still seriously insufficient [2]. However, women's physical inactivity is particularly problematic [3]. Stodden et al. propose the motor skills and physical fitness model, believing that the development of motor skills is the basis of promoting physical activity ${ }^{[4]}$, which has attracted much attention ${ }^{[5,6]}$. fundamental Motor Skills of children included Locomotor Skill (running, jumping, etc.) and Object Control Skill (bouncing ball, catching ball, etc.).Fundamental motor skills are positively correlated with many aspects of health [5]. Children with low fundamental motor skills tend to lack physical activity, have lower cardiopulmonary function, and are more likely to be obese [7]. As a result of regional differences, the study of fundamental motor skills, gender differences there are many different point of view, although the preschool private physical characteristics are similar, but many practice study found: preschool children the fundamental sports skills, there is a lot of gender differences. For China, a country with a 
large multi-ethnic population, ethnic and regional differences may also lead to inconsistencies in research results.

Early childhood connection is an important issue in preschool education all over the world .In order to promote the development of fundamental motor skills of children, scientific, reasonable and feasible courses should be designed according to the development of fundamental motor skills of children at the age of 6 , and a sound motor skill learning and development system should be built .

Based on this, this study aims to use the revised Test of Gross Motor Development 3rd Edition (TGMD-3) to measure the fundamental motor skills level of 6-year-old children in urban Jinhua City, and to conduct in-depth analysis of the gender differences in fundamental motor skills of 6-year-old children.

\section{Materials and Methods}

\subsection{Participants}

Table 1. Participants Characteristics ( $\mathrm{N}=516)$.

\begin{tabular}{|c|c|c|c|c|}
\hline & \multicolumn{2}{|c|}{ Mean \pm SD } & \multirow{2}{*}{$\mathbf{t}$} & \multirow[b]{2}{*}{$p$} \\
\hline & Boys $(n=254)$ & Girls $(n=262)$ & & \\
\hline Age (years) & $6.15 \pm 0.40$ & $6.15 \pm 0.39$ & -0.094 & 0.925 \\
\hline Height $(\mathrm{cm})$ & $118.33 \pm 4.00$ & $118.28 \pm 4.07$ & -0.140 & 0.889 \\
\hline Weight (kg) & $22.19 \pm 3.37$ & $21.97 \pm 3.19$ & -0.804 & 0.422 \\
\hline BMI $\left(\mathrm{kg} / \mathrm{m}^{2}\right)$ & $16.14 \pm 1.52$ & $15.94 \pm 1.51$ & -1.499 & 0.134 \\
\hline
\end{tabular}

Random cluster sampling was used to recruit 516 healthy 6-year-old third-year kindergarten students from one local private kindergarten school in Hangzhou city, Zhejiang Province, China. The subjects were 254 boys and 262 girls (age, $6.15 \pm 0.39$ years; height, $118.31 \pm 4.04 \mathrm{~cm}$; weight, $22.08 \pm 3.28 \mathrm{~kg}$; body mass index [BMI], $16.04 \pm 1.52$ $\mathrm{kg} / \mathrm{m} 2$ ). There were no gender differences in the age, height, weight and BMI of the selected children (table 1, $\mathrm{p}>0.05$ ).

Exclusion criteria were, 1) known developmental disability, 2) obvious deformity and orthopedic injury in both upper and lower extremities within 6 months.3) any illness during testing time.

Information on this study was provided with the Chinese version of the written information letter and by verbal explanation to the director of the school, teachers,parents or guardians, and students before their voluntary participation. Ethical approval was obtained from Faculty of Medicine ethics committee of Zhejiang Normal University (ZSDR2019013).

\subsection{Gross Motor Skills}

Gross Motor Development Test (TGMD) is a process-oriented test of gross motor skills of children aged from 3 to 10 years [20]. In 2000, it was revised to form the second edition of gross Motor Development Test (TGMD-2) [21]. In 2013, Dr. Ulrich revised TGMD-2, In 2015, TGMD-3 scoring form was open to use [24]. Previous studies using the TGMD-3 to assess the gross motor skill development of children in preschool and elementary school have been conducted in different countries $[10,25,26,27,28]$. while the TGMD-3 has shown adequate reliability and validity among Children. The Test of Gross Motor Development, currently in its third edition (TGMD-3), is a valid and reliable tool for assessing 13 FMS (6 locomotor and 7 object-control skills) among children aged 3-10 years-old

During the test, the tester will first demonstrate the movement correctly once, and let the subjects watch it carefully. Then the subjects will complete the test independently according to the movements away the experimenter, and then conduct the second test.If the subject did not understand or perform the test correctly, the same tester provided 
additional demonstrations, and all the actions were measured twice in a row.All skills were tested twice in a row, and each skill was rated on a scale of 3-5, A score of 1 was given for each performance criterion correctly performed and 0 for any absent or incorrectly performed criterion.There are 46 points for mobile skills and 54 points in object control skills, with a full score of 100 .

\subsection{Statistical Analysis}

Descriptive statistics and Independent-samples $\mathrm{T}$ Test of were used to analyze the data. The significance level was set as $p<0.05$. Data analysis was performed using IBM SPSS statistic version 21.0 for Windows.

\section{RESULTS}

\subsection{Sex group Differences in FMS}

Table 2. Comparisons of gross motor skills between boys and girls ( $\mathrm{N}=516)$.

\begin{tabular}{ccccc}
\hline \multirow{2}{*}{ Skill } & \multicolumn{2}{c}{ Mean \pm SD } & \multirow{2}{*}{$\mathbf{t}$} & \multirow{2}{*}{$\boldsymbol{p}$} \\
\cline { 2 - 3 } & Boys (n=254) & Girls (n=262) & & \\
\hline Run & $6.75 \pm 1.16$ & $6.33 \pm 1.20$ & 4.122 & 0.000 \\
Gallop & $5.66 \pm 1.49$ & $5.54 \pm 1.51$ & 0.939 & 0.347 \\
Slide & $5.08 \pm 1.69$ & $5.13 \pm 1.57$ & -0.327 & 0.748 \\
Skip & $4.44 \pm 1.51$ & $4.71 \pm 1.36$ & -2.177 & 0.031 \\
Horizontal Jump & $4.27 \pm 1.68$ & $4.40 \pm 1.73$ & -0.887 & 0.374 \\
Hop & $5.37 \pm 1.73$ & $5.46 \pm 1.55$ & -0.701 & 0.483 \\
Overhand throw & $5.20 \pm 1.81$ & $5.21 \pm 1.70$ & -0.072 & 0.944 \\
Underhand throw & $4.45 \pm 2.11$ & $3.87 \pm 2.00$ & 3.318 & 0.001 \\
Two Hand Catch & $3.61 \pm 1.73$ & $3.23 \pm 1.57$ & 2.721 & 0.006 \\
One Hand Stationary dribble & $4.24 \pm 1.30$ & $4.38 \pm 1.08$ & -1.377 & 0.169 \\
Forehand Strike of Self-bounced & $3.81 \pm 1.31$ & $3.60 \pm 1.15$ & 2.030 & 0.042 \\
Ball & $3.64 \pm 1.92$ & $2.91 \pm 1.65$ & 4.794 & 0.000 \\
Two Hand a Stationary Ball & $5.42 \pm 1.63$ & $4.86 \pm 1.61$ & 4.009 & 0.000 \\
Kick a Stationary Ball & $31.57 \pm 6.06$ & $31.57 \pm 5.88$ & -0.008 & 0.995 \\
Locomotor & $30.12 \pm 7.83$ & $28.05 \pm 6.45$ & 3.37 & 0.002 \\
Ball Skills & $61.75 \pm 11.73$ & $59.70 \pm 10.60$ & 2.15 & 0.033 \\
FMS & & & &
\end{tabular}

As can be seen from the above table, there was almost no difference between boys and girls in the locomotor skills of 6-year-old children $(\mathrm{P}>0.993)$. The object control skill of girls was higher than that of boys $(\mathrm{P}=0.001)$. The gender difference in FMS was statistically significant $(\mathrm{P}=0.032)$.In the locomotor skill, boys were better than girls in the running $(p=0.000)$ and girls were better than boys in the skip $(p=0.030)$. In the object control skill, boys were better than girls in the underhand throw $(\mathrm{p}=0.001)$, two hand catch $(\mathrm{p}=0.007)$,forehand strike self-bounced ball $(\mathrm{p}=0.043)$, two-handed strike of a stationary ball $(\mathrm{p}=0.000)$,kick a stationary ball $(\mathrm{p}=0.000)$.

\section{Discussion}

There are gender differences in some fundamental motor skills of 6-year-old children. The formation and development of the differences had biological and sociological reasons. It is suggested to strengthening the training of girls' object control motor skills and improve the level of Moderate-to-vigorous physical activity among females.

Funding: This study was funded by the Zhejiang Provincial Welfare Technology Application Research Project of China, grant number 2017C3076. 
Acknowledgments: Thanks to 7 kindergartens in Hangzhou for participation in this intervention.

Conflicts of Interest: No conflict of interest was declared.

\section{References}

1. POWELL KE, KING AC, BUCHNER DM, et al. The scientific foundation for the physical activity guidelines for Americans, 2nd Edition[J]. J Phys Act Health, 2019,16:1-11.

2. REGINA GUTHOLD P, GRETCHEN A STEVENS D, LEANNE M RILEY M, et al. Global trends in insufficient physical activity among adolescents: a pooled analysis of 298 population based surveys with 1.6 million participants[J]. Lancet Child Adolesc, 2020,4: 23-35.

3. Huan Zhang, Baolin Dong. Influence of sports friendship, autonomous motivation and gender role on adolescent exercise Persistence [J].Journal of Tian Jin university of physical education. 2017,32: 355-363.

4. STODDEN DFDB, GOODWAY JD, LANGENDORFER SJ, et al. A developmental perspective on the role of motor skill competence in physical activity: An Emergent Relationship[J]. QUEST, 2008,60:290-306.

5. BARNETT LM,LAI SK,VELDMEN SL, et al. Correlates of gross motor competence in children and adolescents: a systematic review and meta-analysis[J]. Sports Med,2016, $46: 1663-1688$.

6. UTESCH T, BARDID F, UUML B, et al. The relationship between motor competence and physical fitness from early childhood to early adulthood: A Meta-Analysis[J]. Sports Med, 2019,49:541-551.

7. FIELD SC, TEMPLE VA. The relationship between fundamental motor skill proficiency and participation in Organized Sports and Active Recreation in middle childhood[J]. Sports 2017,5:43.

8. Yucui Diao,Cuixiang Dong,Jing Li. Establishment of Norms for gross motor Development test in Shanghai [J].China Sports Science and Technology, 2008,54: 98-104.

9. MAENG HJ, WEBSTER EK, ULRICH DA. Reliability for the test of gross motor development-third Edition (TGMD-3)[J]. Res Q Exercise Sport, 2016,87:A38.

10. ULRICH D A. The test of gross motor development-3(TGMD-3): Administration, scoring, and international norms[J]. Spor Bilimleri Dergisi, 2013,2:27-33.

11. PALMER KK, CHINN KM, ROBINSON LE. He effect of the CHAMP intervention on fundamental motor skills and outdoor physical activity in preschoolers[J]. J Sport Health Sci, 2019,8:98-105.

12. WEBSTER EK,ULRICH DA,. Evaluation of the psychometric properties of the test of gross motor development-3rd edition[J]. J Motor Learn Dev, 2017,5:45-58.

13. VALENTINI NCA, ZANELLA LWA, WEBSTER EKB. Test of gross motor development third edition: Establishing content and construct validity for Brazilian children(Article)[J]. J Motor Learn Dev, 2017,5:15-28.

14. ESTEVAN IA, MOLINA-GARCÍA JA, QUERALT AB, et al. Validity and reliability of the Spanish version of the test of gross motor development-3(Article)[J]. J Motor Learn Dev, 2017, 5:69-81. 